\title{
Influence of Curing Light Attenuation Caused by Aesthetic Indirect Restorative Materials on Resin Cement Polymerization
}

\author{
Bárbara Pick ${ }^{a}$ \\ Carla Castiglia Gonzaga ${ }^{b}$ \\ Washington Steagall Junior ${ }^{c}$ \\ Yoshio Kawano ${ }^{d}$ \\ Roberto Ruggiero Braga ${ }^{a}$ \\ Paulo Eduardo Capel Cardoso ${ }^{a}$
}

\begin{abstract}
Objectives: To verify the effect of interposing different indirect restorative materials on degree of conversion (DC), hardness, and flexural strength of a dual-cure resin cement.

Methods: Discs (2 mm-thick, $n=5$ ) of four indirect restorative materials were manufactured: a layered glass-ceramic (GC); a heat-pressed lithium disilicate-based glass-ceramic veneered with the layered glass-ceramic (LD); a micro-hybrid (MH); and a micro-filled (MF) indirect composite resin. The light transmittance of these materials was determined using a double-beam spectrophotometer with an integrating sphere. Bar-shaped specimens of a dual-cure resin cement (Nexus 2/SDS Kerr), with (dual-cure mode) and without the catalyst paste (light-cure mode), were photoactivated through the discs using either a quartz-tungsten-halogen (QTH) or a light-emitting diode (LED) unit. As a control, specimens were photoactivated without the interposed discs. Specimens were stored at $37^{\circ} \mathrm{C}$ for $24 \mathrm{~h}$ before being submitted to FT-Raman spectrometry $(n=3)$, Knoop microhardness $(n=6)$ and threepoint bending $(n=6)$ tests. Data were analyzed by ANOVA/Tukey's test ( $\alpha=0.05)$.

Results: MH presented the highest transmittance. The DC was lower in light-cure mode than in dual-cure mode. All restorative materials reduced the cement microhardness in light-cure mode. GC and LD with QTH and GC with LED decreased the strength of the cement for both activation modes compared to the controls. Curing units did not affect DC or microhardness, except when the dualcure cement was photoactivated through LD (LED>QTH). Flexural strength was higher with QTH compared to LED.

Conclusions: Differences in transmittance among the restorative materials significantly influenced cement DC and flexural strength, regardless of the activation mode, as well as the microhardness of the resin cement tested in light-cure mode. Microhardness was not impaired by the interposed materials when the resin cement was used in dual-cure mode. (Eur J Dent 2010;4:314-323)
\end{abstract}

Key words: Light transmission; Resin cement; Degree of conversion; Microhardness; Flexural strength.

\footnotetext{
- a Department of Dental Materials, University of São Paulo, Brazil.

b Masters Program in Clinical Dentistry, Positivo University, Brazil.

Department of Restorative Dentistry, University of São Paulo, Brazil.

d Chemical Institute, University of São Paulo, Brazil.
}

- Corresponding author: Bárbara Pick Av. Prof. Lineu Prestes, 2227. Cidade Universitária. 05508-000. São Paulo, SP, Brazil. Phone: 554199796310 Fax: 551130917840 E-mail: barbaraApick.com.br 


\section{INTRODUCTION}

Resin cements are used for luting all-ceramic and composite indirect restorations due to their excellent mechanical properties, the possibility of their bonding to the tooth structure, and improved aesthetics compared to conventional cements. ${ }^{1-5}$ In order to maximize the clinical performance of indirect aesthetic restorations, it is crucial to observe some aspects that may affect resin cement polymerization, such as the optical behavior of the restorative material, ${ }^{6-8}$ the resin cement activation mode, ${ }^{9-11}$ and the characteristics of the light curing unit used for cement photoactivation. ${ }^{12,13}$

When visible light reaches the restorative material, part of the light is transmitted through it, part is absorbed, and part is reflected on the surface. The level of opacity of a given material depends on its internal reflectance and transmittance. Opacity is the result of high light scattering with a very low fraction of the incident beam being transmitted through the material. ${ }^{14}$ In biphasic materials, such as composites and ceramics, light scattering occurs at interfaces with different refraction indexes. In this case, the greater the difference of refraction indexes, the greater the scattering. ${ }^{14}$ The optical behavior of indirect aesthetic materials also depends on their inorganic content, matrix composition, and particle size, as well as the presence of pores incorporated during the processing of the material. ${ }^{14-16}$

The light transmittance through an indirect restorative material can greatly affect the polymerization of resin cements. ${ }^{17,18}$ In photoactivated cements, the initiation system is composed of one or more photoinitiators, such as camphorquinone (CQ) and a tertiary amine ( N,N-dimethylaminoethyl methacrylate). ${ }^{18}$ In composites that contain $C Q$, light irradiation with wavelengths ranging between 470 and $480 \mathrm{~nm}^{19,20}$ leads CQ to a "triplet" state. In this state, $C Q$ is capable of combining with two amine molecules, forming a photoexcitated complex ("exciplex"). After CQ removes a proton from each amine molecule, the "exciplex" breaks into free radicals that will react with the monomer carbon-carbon double bonds, initiating the polymerization reaction. If an insufficient number of $C Q$ molecules reach the "triplet" state, the composite will not be properly cured..$^{17,18}$

In dual-cure systems, a catalyst paste containing a chemical activator (benzoyl peroxide (BP)) can be mixed with the light-cured resin cement to increase free radical concentration even under insufficient light. When the two pastes are mixed together and exposed to light, free radicals are formed both by photo- and chemical-activation. It is expected that in areas where light is partially or totally attenuated, the free radicals formed by amine/BP interaction would compensate for the lack of those that result from amine/CQ interaction. ${ }^{11}$

Besides formulation $n^{7,10,21,22}$ and opacity ${ }^{23}$ of the indirect restorative material, other factors that interfere with the radiant exposure that reaches the cement layer are the restoration thickness $5^{7,10,21,23-26}$ and shade, ${ }^{6,24}$ the distance between curing unit light guide and cement layer, ${ }^{23}$ the curing protocol used, ${ }^{27,28}$ and the light curing unit., $73,24,28,29$ Light-emitting diode (LED) and quartz-tungstenhalogen (QTH) curing units can provide irradiances from 300 to $1200 \mathrm{~mW} / \mathrm{cm}^{2}$ with the former providing a much narrower spectral emission that better matches the absorption band of $C Q .{ }^{30,31}$ The effects of irradiance, light curing time, and type of curing unit (QTH and LED) on the hardening of various resin cements have been determined. ${ }^{32}$ High-intensity light curing and longer curing times increase cement microhardness. The use of LED units resulted in resin cement microhardness similar to that achieved with conventional QTH. ${ }^{32}$ However, in direct restorative composites, the use of an LED unit promoted a lower depth of cure than QTH, which was associated with differences in light scattering due to differences in spectral emission. ${ }^{31}$

The aim of this study was to evaluate the light transmittance of indirect aesthetic restorative materials and to verify its influence on the degree of conversion (DC), Knoop microhardness, and flexural strength of a resin cement that was tested either in dual-cure or light-cure mode after its photoactivation with a QTH or an LED curing unit. The tested hypotheses were: 1) light attenuation caused by interposed indirect restorative materials impairs the evaluated properties of the resin cement in light-cure mode but not in dual-cure mode; 2$)$ resin cement properties are influenced by differences in irradiance and spectral emission found in a QTH and an LED light unit. 


\section{MATERIALS AND METHODS}

Aesthetic restorative materials

Five disc-shaped specimens $111.0 \mathrm{~mm}$ of diameter and $2.0 \pm 0.1 \mathrm{~mm}$ of thickness) of four indirect aesthetic restorative materials were prepared: a layered glass-ceramic (GC), a heat-pressed lithium disilicate-based glass-ceramic $10.8 \mathrm{~mm}$ of thickness) veneered with the same layered glassceramic (1.2 mm of thickness) (LD), a micro-hybrid (MH) and a micro-filled (MF) indirect composite (Table 1).

For GC, the specimens were prepared by the vibration-condensation method using a stainless steel mold $(14.9 \mathrm{~mm}$ of diameter and $2.9 \mathrm{~mm}$ of thickness) and sintered in a dental porcelain furnace (Keramat I, Knebel, Porto Alegre, Brazil), following the firing schedules recommended by the manufacturer. After firing, the specimens were cut to obtain $11.0 \mathrm{~mm}$ diameter using a diamond bur, and the thickness of $2.0 \mathrm{~mm}$ was achieved using a grinding machine (MSG-600, Mitutoyo, São Paulo, Brazil). Specimens in the LD group were prepared as bi-layers. Lithium disilicate-based glass-ceramic discs were processed by the heatpress technique using a specific oven (EP 600, Ivoclar Vivadent, Schaan, Liechtenstein), following the firing schedules recommended by the manufacturer. The specimens were ground to a $0.8 \mathrm{~mm}$ thickness using a grinding machine. The same glass-ceramic used in the GC group was applied to one surface of the disc. The specimens were cut using a diamond bur to obtain a diameter of 11.0 $\mathrm{mm}$. A final $2.0 \mathrm{~mm}$ thickness was achieved using a grinding machine.
For $\mathrm{MH}$ group, a polyethylene mold was used to incrementally build the spacer to a diameter of $11.0 \mathrm{~mm}$ and a thickness of $2.0 \mathrm{~mm}$. Each of the four increments of composite resin was photoactivated for 5 s (Visio Alfa, 3M ESPE, Seefeld, Germany). The last increment was inserted into the mold, pressed by a glass slide, and photoactivated for $40 \mathrm{~s}$ with the same curing unit. The disc was removed from the mold and placed into a second curing unit (Visio Beta Vario, 3M ESPE, Seefeld, Germanyl for 15 min under light and vacuum. The same polyethylene mold was used for specimens in the MF group, but the composite resin was inserted into the mold in only one increment, which was pressed by a glass slide and photoactivated for 40 s lQuick curing unit, Ivoclar-Vivadent, Leichtenstein). The disc was removed from the mold and placed into a second curing unit (Targis Power Upgrade, Ivoclar-Vivadent, Leichtenstein) for 25 min under light and vacuum. All materials had the Vita A2 shade (Vita Zahnfabrik, Bad Säckingen, Germanyl, and both surfaces were polished using sandpaper with a sequence of decreasing grit under constant water irrigation and a felt disc with 1 $\mu \mathrm{m}$ diamond paste (Buehler, Lake Bluff, USA).

\section{Light transmittance analysis}

The total spectral transmittance of the aesthetic restorative materials, defined as the sum of the directly transmitted light and diffuse transmission by scattering, ${ }^{33}$ was determined by a double-beam spectrophotometer (Cintra 10, CBC Scientific Equipment, Dandenong, Australial equipped with an integrating sphere, from 380 to $780 \mathrm{~nm}$ wave-

Table 1. Indirect aesthetic restorative materials tested ${ }^{*}$

\begin{tabular}{|c|c|c|c|c|c|c|}
\hline Group & Material & Composition & Inorganic content & Particle size $(\mu \mathrm{m})$ & Particle by weight (\%) & Batch \# \\
\hline GC & $\begin{array}{l}\text { IPS Eris, Ivoclar- } \\
\text { Vivadent, Schaan, } \\
\text { Leichtenstein }\end{array}$ & $\begin{array}{l}\text { Glass-ceramic containing } \\
\text { fluorapatita and alkali- } \\
\text { zinc-silicate }\end{array}$ & Not informed & Not informed & Not informed & H25269 \\
\hline LD & $\begin{array}{l}\text { IPS Empress 2: } \\
\text { veneered by IPS Eris, } \\
\text { Ivoclar-Vivadent, } \\
\text { Schaan, Leichtenstein }\end{array}$ & $\begin{array}{l}\text { IPS Empress 2: } \\
\text { glass-ceramic reinforced } \\
\text { by lithium disilicate } \\
\text { IPS Eris: described above }\end{array}$ & $\begin{array}{l}\text { IPS Empress 2: } \\
\text { lithium disilicate } \\
\text { IPS Eris: not informed }\end{array}$ & $\begin{array}{c}\text { IPS Empress 2: } \\
0.5-4.0 \\
\text { IPS Eris: not informed }\end{array}$ & $\begin{array}{l}\text { IPS Empress 2: } \\
70 \pm 5 \\
\text { IPS Eris: not informed }\end{array}$ & $\begin{array}{l}\text { IPS Empress 2: } \\
\text { J06266 } \\
\text { IPS Eris: H25269 }\end{array}$ \\
\hline $\mathrm{MH}$ & $\begin{array}{l}\text { Sinfony, 3M ESPE, } \\
\text { Seefeld, Germany }\end{array}$ & $\begin{array}{l}\text { UDMA'}^{1} \text {-based ultra-fine } \\
\text { particle hybrid composite }\end{array}$ & $\begin{array}{l}\text { Strontium aluminium } \\
\text { borosilicate glass; } \\
\text { Pyrogenic silica }\end{array}$ & $0.5-0.7 ; 0.06$ & $40 ; 5$ & 253241 \\
\hline MF & $\begin{array}{c}\text { SR Adoro, } \\
\text { Ivoclar-Vivadent, } \\
\text { Schaan, Leichtenstein }\end{array}$ & $\begin{array}{l}\text { UDMA }^{1} \text {-based microfilled } \\
\text { composite }\end{array}$ & Silicon dioxide & $0.01-0.1$ & $46-47$ & $\mathrm{H} 2236$ \\
\hline
\end{tabular}


length range, at $2 \mathrm{~nm}$ intervals $(\mathrm{n}=5)$. A polished aluminum sample holder was used. For each restorative material, the total transmittance in a wavelength interval between 400 and $500 \mathrm{~nm}$ was calculated as the average of three measurements.

\section{Light curing unit characterization}

A quartz-tungsten-halogen curing unit $(Q T H$, OptiluxTM 501, SDS Kerr, Orange, USAl and a light-emitting diode (LED, L.E.Demetron 1, SDS Kerr, Orange USAl were selected for use in this study, and their spectral emission and irradiance were determined by a spectroradiometer (Photo Research, model PR-705, series 75033201, Chatsworth, USA) with an integrating sphere (0ptronic, model OL IS-670, series 96100046, Orlando, USA). Three measurements were performed in a wavelength range between 380 and $780 \mathrm{~nm}$, at 2 $\mathrm{nm}$ intervals.

\section{Specimen preparation}

Bar-shaped specimens $110 \mathrm{~mm}$ length $x 2 \mathrm{~mm}$ width $\times 1 \mathrm{~mm}$ height) were prepared in a metallic mold using only the light-curable paste of the dual-cure resin cement (light-cure mode, Table 2) or the dual-curable paste mixture of the same resin cement (i.e., with catalyst paste, dual-cure mode, Table 2). For the dual-cure mode, base and catalyst pastes were weighted equally on an analytical balance, with $0.0001 \mathrm{~g}$ accuracy (Adventure, Ohaus, China). For both light-cure and dual-cure modes, specimens were photoactivated between two polyester strips and through the indirect restorative materials discs. To guarantee the correct position of the restorative material disc, curing unit tip and resin cement specimen, a black polyacetal device was used (Figure 1). As a control, light-cure and dual-cure specimens were photoactivated without any interposed restorative material, with the curing unit light guide placed at a $2 \mathrm{~mm}$ distance from the cement surface. Half of the specimens were photoactivated with the QTH (Optilux ${ }^{\mathrm{TM}}$ 501, SDS Kerr, Orange, USA) and the other half with the LED (L. E. Demetron 1, SDS Kerr, Orange, USA), both for $60 \mathrm{~s}$, as the minimum recommended by the resin cement manufacturer is $40 \mathrm{~s}$. After photoactivation, each specimen had the irradiated surface identified and its dimensions were checked using a digital caliper (Starrett, Itu, Brazil). The specimens were stored in the dark with distilled water at $37^{\circ} \mathrm{C}$ for $24 \mathrm{~h}$.

\section{Degree of conversion}

Three specimens from each experimental group were used for DC evaluation. All specimens' surfaces were polished in a semi-automatic polisher (Twin Variable Speed Grinder Polisher EcoMet and Power Head AutoMet 2000, Buehler, Lake Bluff, USA), under constant water irrigation, using a 4000 grit sandpaper for 2 min. An FT-Raman spectrometer equipped with a $100 \mathrm{~mW}, 1064$ nm Nd:YAG laser source (model RFS 100/S, Bruker Optics, Billerica, USA) was used to obtain spectra in the 1000 to $2000 \mathrm{~cm}^{-1}$ interval by co-addition of 64 scans at a spectral resolution of $4 \mathrm{~cm}^{-1}$. DC of each specimen was the average of four measurements, two performed at the irradiated and two at the non-irradiated surface. The ratio (R) between aliphatic (1640 $\left.\mathrm{cm}^{-1}\right)$ and aromatic $\left(1610 \mathrm{~cm}^{-1}\right)$ carbon double bond bands was used to calculate the $D C$, according to the formula: ${ }^{34}$

$$
D C=\left(1-R_{\text {cured }} / R_{\text {non-cured }}\right) \times 100 \text {. }
$$

\section{Knoop microhardness}

Knoop microhardness ( $n=6$ ) was determined on the lateral surface of the specimens. The surfaces were polished as described above for the DC specimens. Knoop microhardness of each specimen was calculated as the average of the six indentations made using a microhardness tester (Shimadzu, model HMV - 2T, Kyoto, Japan) with a load of $100 \mathrm{~g}$ and a dwell time of $15 \mathrm{~s} .{ }^{35}$

Table 2. Resin cement tested*.

\begin{tabular}{|c|c|c|c|c|c|c|}
\hline Material & Manufacturer & Composition & Inorganic content & Particle size $(\mu \mathrm{m})$ & $\begin{array}{c}\text { Particle by weight } \\
\qquad(\%]\end{array}$ & Batch \# \\
\hline $\begin{array}{l}\text { Nexus } 2 \text { base paste } \\
\text { (clear shade) }\end{array}$ & $\begin{array}{c}\text { SDS Kerr, } \\
\text { Orange, USA }\end{array}$ & $\begin{array}{l}\text { Bis-GMA }{ }^{1} ; \\
\text { TEGDMA }^{2}\end{array}$ & Silicon dioxide & 0.6 & 47 & 436600 \\
\hline $\begin{array}{l}\text { Nexus } 2 \text { catalyst paste } \\
\text { (low viscosity) }\end{array}$ & $\begin{array}{l}\text { SDS Kerr, } \\
\text { Orange, USA }\end{array}$ & $\begin{array}{l}\text { Bis-GMA', TEGDMA², } \\
\text { benzoyl peroxide }\end{array}$ & Not informed & Not informed & Not informed & 432687 \\
\hline
\end{tabular}

* Information provided by manufacturers.

'A-diglycidyl-dimetacrylate.

${ }^{2}$ Triethylene glycol dimethacrylate. 


\section{Flexural strength}

Flexural strength $(n=6)$ was obtained using a three-point bending test in a universal test machine (Kratos, Cotia, SP, Brazil) with a crosshead speed of $0.5 \mathrm{~mm} / \mathrm{min}$. The flexural strength ( $\sigma=)$, in MPa, was calculated using the following equation: ${ }^{11,36}$

$$
\sigma=\frac{3 P L}{2 w h^{2}}
$$

where $P$ is the maximum load at the point of fracture (N), L the span length $(6 \mathrm{~mm})$, w the width of the sample, and $h$ its height.

\section{Statistical analysis}

Transmittance data was analyzed by one-way analysis of variance (ANOVA). DC, Knoop microhardness, and flexural strength data were submitted to three-way ANOVA with curing unit, resin cement activation mode, and restorative materials as independent variables. Tukey's test was used for multiple comparisons. Tests were performed with a pre-set global significance of $5 \%$.

\section{RESULTS}

Total transmittance analysis and light curing unit characterization

Figure 2 shows the transmittance spectra of the aesthetic restorative materials. For all materials, transmittance increased at higher wavelengths. Light transmittance in the 400 to $500 \mathrm{~nm}$ range was higher for $\mathrm{MH}\left(3.50 \pm 0.31 \%{ }^{\mathrm{a}}, \mathrm{P}<.001\right)$, followed by MF (2.15 $\pm 0.22 \%$ b), LD $(1.93 \pm 0.23 \%$ bc $)$, and $G C(1.63 \pm 0.21 \% c)$.

Figure 3 shows the emission spectra of the QTH and LED units. The maximum irradiance of QTH was situated at $492 \mathrm{~nm}$, while for the LED it was at $452 \mathrm{~nm}$. Total irradiances were $750 \mathrm{~mW} /$ $\mathrm{cm}^{2}$ for QTH and $1060 \mathrm{~mW} / \mathrm{cm}^{2}$ for LED.

\section{Degree of conversion}

Table 3 shows the DC means and standard deviations as a function of curing unit, cement activation mode, and restorative material. None of the interactions was statistically significant ( $P>$.05). Moreover, DC was not significantly affected by the curing unit $(P=0.698)$. Dual-cured specimens presented higher DC than light-cured $174.1 \pm 3.3 \%$ and $64.9 \pm 4.5 \%$, respectively, $P<.001$ ). Regarding the restorative materials, there was no statisti- cal difference among the control (72.7 $44.0 \%$ a), $\mathrm{MH}$ $(70.1 \pm 4.9 \%$ ab) and MF $(68.9 \pm 6.7 \%$ ab,$P<.01)$. However, GC $\left(67.4 \pm 6.8 \%^{\mathrm{b}}\right)$ and LD $\left(68.2 \pm 6.9 \%^{\mathrm{b}}\right)$ presented lower DC than the control.

\section{Knoop microhardness}

Table 3 shows Knoop microhardness means and standard deviations as a function of curing unit, resin cement activation mode, and restorative material interaction. The triple-order interaction was statistically significant $(P<$.001). The control groups were not affected by any curing unit/resin cement activation mode combinations. Dual-cure mode specimens presented higher Knoop microhardness than light-cure for all curing unit/restorative material combinations. In general, hardness values obtained by the dual-cured cement were similar to the control, except for LDQTH. When the cement was light-cured, none of the restorative material/curing unit combinations reached hardness similar to the control. The curing units did not influence the Knoop microhardness values of the light-cured cement. The Knoop microhardness values for the dual-cured cement were not affected by the curing unit, except for LD (LED>QTH).

\section{Flexural strength}

The statistical analysis for the flexural strength test detected significant differences only for the main factors $(P<.001)$. Table 3 shows the flexural strength means and standard deviations as a function of curing unit, cement activation mode, and restorative material interaction. When tested in dual-cure mode, the flexural strength mean was higher than in the light-cure mode (199.4 \pm 36.5

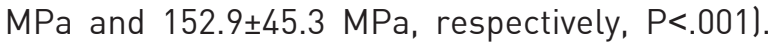
Furthermore, the use of the QTH resulted in higher strength than the LED unit (194.5 $\pm 45.2 \mathrm{MPa}$ and

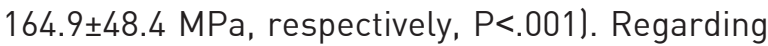
the restorative materials, $\mathrm{MH}\left(198.7 \pm 33.8 \mathrm{MPa}^{\mathrm{ab}}\right)$ allowed a flexural strength similar to the control

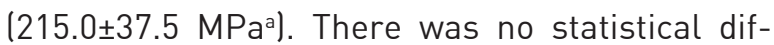
ference between $\mathrm{MH}$ and MF $\left(186.7 \pm 37.6 \mathrm{MPa}^{\mathrm{bc}}\right)$ or between the latter and LD (171.2 $\left.\pm 42.2 \mathrm{MPa}^{\mathrm{C}}\right)$. Specimens photoactivated through GC (126.8 \pm 44.0 $\mathrm{MPa}^{\mathrm{d}}$ ) showed the lowest flexural strength value for the resin cement $(P<.001)$. 


\section{DISCUSSION}

The first hypothesis of this study, which stated that the light attenuation caused by the indirect restorative materials impairs the evaluated properties of the resin cement in light-cure mode but not in dual-cure mode, was partially proven. For $D C$, in spite of the fact that the light-cure mode showed lower values than the dual-cure mode, the interaction between the cement activation mode and the restorative material was not statistically significant. Therefore, it is not possible to affirm that the attenuation caused by the restorative materials was the sole factor responsible for the lower DC of the resin cement in light-cure mode.
On the other hand, the attenuation caused by all the restorative materials reduced cement microhardness in light-cure mode, while the self-cure activator present in the dual-cure mode helped to keep KHN similar to the control, except in the LD/QTH group. Finally, light attenuation caused a reduction of the cement flexural strength for both activation modes for three specific material/light unit combinations (namely, GC/QTH, LD/QTH, and GC/LED). Many studies comparing both activation modes showed that the chemical activation in combination with photoactivation guarantees better properties in the resin cement. 11,19,28,37-40

The amount of light reflected, absorbed, and

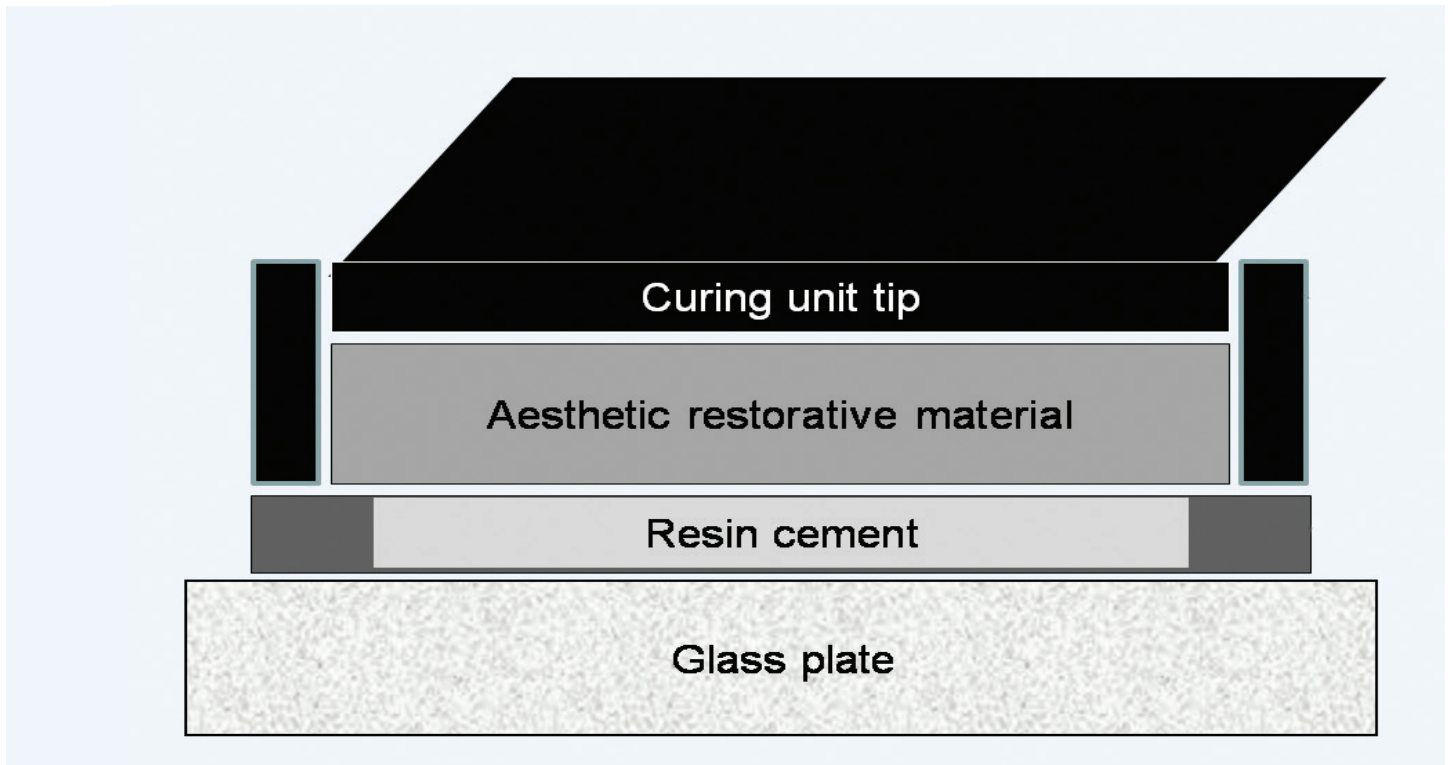

Figure 1. Set-up for the resin cement specimen preparation.

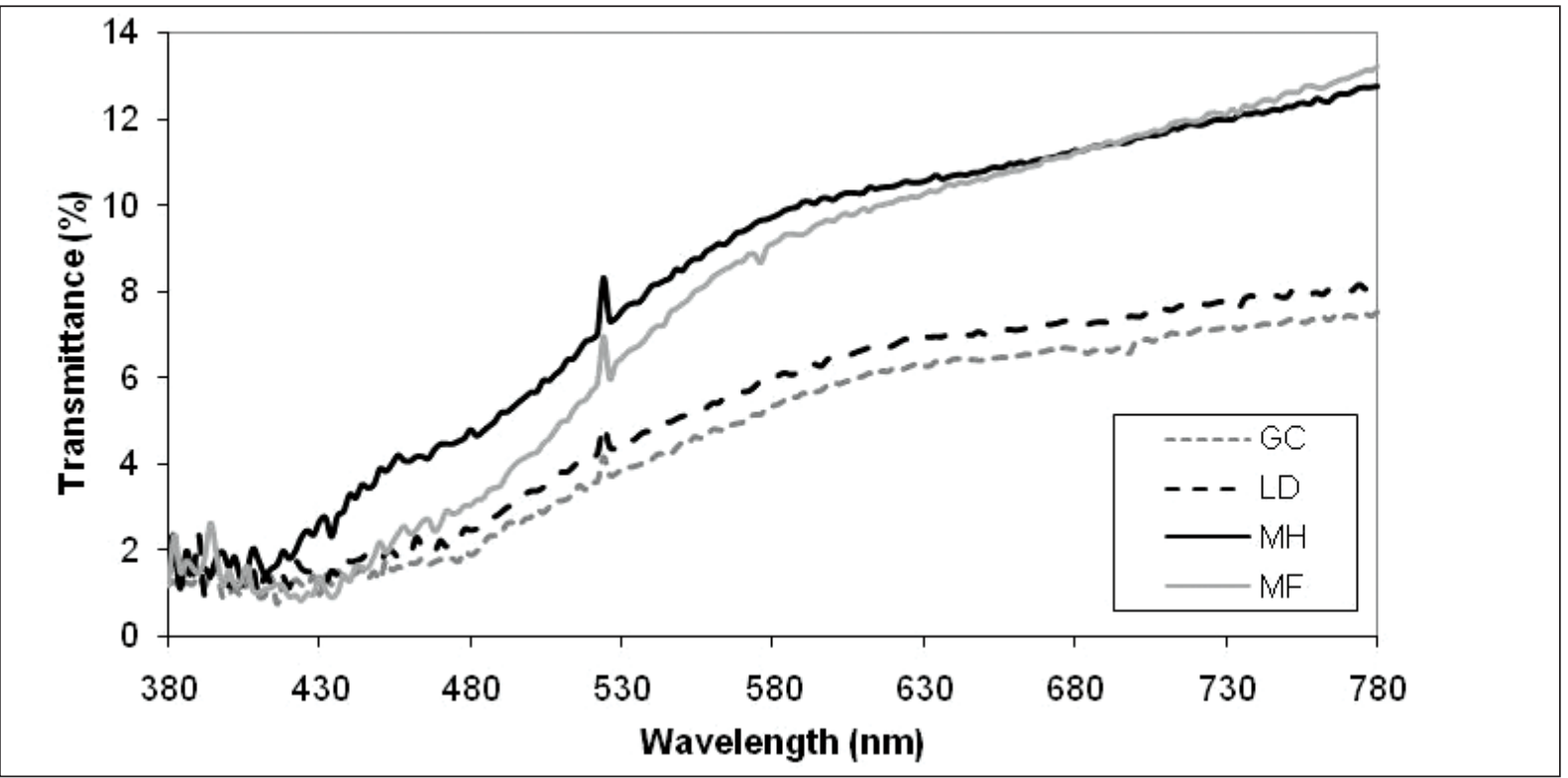

Figure 2. Total transmittance spectra of the aesthetic restorative materials evaluated. The spectrum of each material was obtained based on the mean values at $2 \mathrm{~nm}$ wavelength intervals. 
transmitted depends on the number and size of particles and pores within the matrix. ${ }^{41} \mathrm{MH}$ presented the highest transmittance, while no statistical differences were found between MF and LD and between LD and GC. The statistical difference in transmittance between $\mathrm{MH}$ and MF may be related to their filler size. With smaller particle sizes, more interfaces are present and, consequently, more scattering will occur, increasing the composite opacity in the wavelength range studied. ${ }^{15}$ Previous studies concerning the relationship between light scattering and composite particle size indicated that bigger fillers allowed deeper composite resin polymerization, ${ }^{42}$ which corresponds with the fact that the $\mathrm{MH}$ composite, which has larger particles than MF resin, transmitted more light.

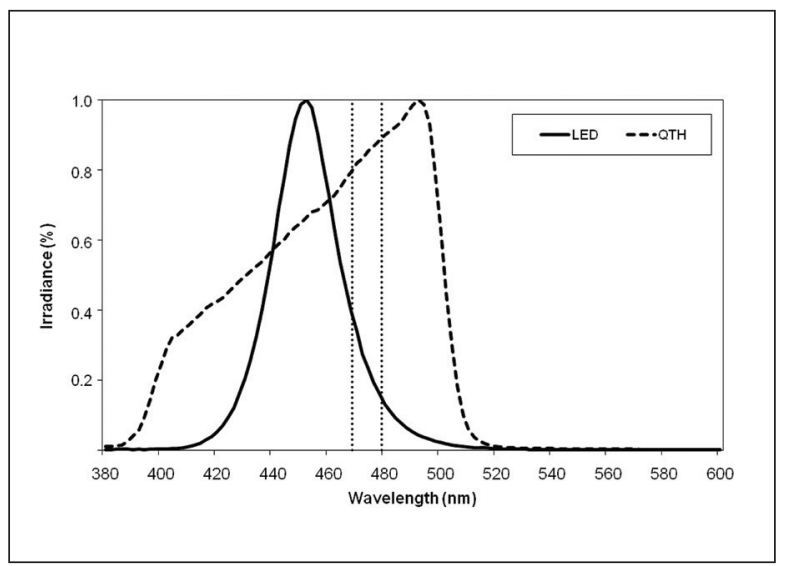

Figure 3. Spectral emission of the quartz-tungsten-halogen curing unit IQTH, Optilux ${ }^{T M}$ 501/SDS Kerr, USA) and the light-emitting diode (LED, L. E. Demetron 1, SDS Kerr, USA) tested. The vertical dotted lines correspond to the camphorquinone absorbance range.
Considering the statistically significant data, differences in transmittance among the restorative materials were reflected in DC and flexural strength results, irrespective of the resin cement activation mode, as well as in Knoop microhardness of the resin cement specimens tested in light-cure mode. The higher the material's transmittance, the higher the irradiance reaching the cement surface, which increased its DC and mechanical properties. Indeed, both $\mathrm{MH}$ and $\mathrm{MF}$ allowed the resin cement to reach a DC similar to the control. In addition, with one exception, Knoop microhardness was higher when the resin cement in light-cure mode was photoactivated through the composite resins rather than the ceramics.

Similar findings were reported in a previous study. ${ }^{40}$ However, other studies disagree with the present results, showing that cement DC and microhardness were lower when photoactivated through a composite compared to porcelain spacers. ${ }^{10,37}$ Such inconsistencies can be explained by the different refraction indexes and surface roughness between composite and ceramic, which are consequences of their distinct natures. ${ }^{40}$ The incident intensity is the sum of the transmitted, absorbed, and reflected light. ${ }^{14}$ Therefore, differences in the surface finishing in the composite and ceramic and the presence of molecules that absorb radiation in the surface layer in the ceramics contributed to an increase in the reflectance and/ or absorbance and, consequently, decreased the transmittance of the ceramics. ${ }^{43}$

Table 3. Mean and standard deviation of degree of conversion, Knoop microhardness and flexural strength values as a function of curing unit, cement activation mode and restorative material interaction. Columns with same letters indicate absence of statistical difference ( $P>05)$

\begin{tabular}{|c|c|c|c|c|c|c|c|}
\hline \multirow{2}{*}{ Curing unit } & \multirow{2}{*}{$\begin{array}{c}\text { Restorative } \\
\text { material }\end{array}$} & \multicolumn{2}{|c|}{ Degree of conversion (\%) } & \multicolumn{2}{|c|}{ Knoop microhardness (KHN) } & \multicolumn{2}{|c|}{ Flexural strength (MPa) } \\
\hline & & Light-cure & Dual-cure & Light-cure & Dual-cure & Light-cure & Dual-cure \\
\hline \multirow{5}{*}{ QTH } & Control & $70.2 \pm 1.8^{\mathrm{abc}}$ & $76.0 \pm 2.2^{\mathrm{a}}$ & $43.9 \pm 1.0^{\mathrm{AB}}$ & $43.8 \pm 0.5^{\mathrm{AB}}$ & $218 \pm 29^{b}$ & $247 \pm 23^{a}$ \\
\hline & $\mathrm{GC}$ & $61.1 \pm 2.9 c$ & $75.0 \pm 1.2^{\mathrm{ab}}$ & $19.3 \pm 4.6^{H}$ & $40.3 \pm 1.0^{\mathrm{BC}}$ & $110 \pm 19^{\mathrm{fg}}$ & $182 \pm 11^{\text {bcd }}$ \\
\hline & LD & $61.9 \pm 1.5^{c}$ & $71.4 \pm 8.5^{\mathrm{abc}}$ & $23.4 \pm 2.3^{\mathrm{GH}}$ & $32.1 \pm 4.4^{\mathrm{DEF}}$ & $158 \pm 32^{\text {cdef }}$ & $212 \pm 32^{b}$ \\
\hline & $\mathrm{MH}$ & $67.3 \pm 3.1^{\mathrm{abc}}$ & $73.7 \pm 2.9^{\mathrm{ab}}$ & $34.3 \pm 1.6^{\mathrm{DE}}$ & $41.8 \pm 2.8^{\mathrm{ABC}}$ & $166 \pm 24^{\text {bcde }}$ & $240 \pm 14^{a}$ \\
\hline & MF & $64.7 \pm 0.1^{\mathrm{bc}}$ & $75.3 \pm 1.0^{\mathrm{ab}}$ & $29.3 \pm 2.1 \mathrm{EF}$ & $48.2 \pm 1.0^{\mathrm{A}}$ & $187 \pm 12^{\mathrm{bcd}}$ & $224 \pm 9$ ab \\
\hline \multirow{5}{*}{ LED } & Control & $69.6 \pm 5.1^{\mathrm{abc}}$ & $74.9 \pm 2.6^{\mathrm{ab}}$ & $44.2 \pm 1.5^{\mathrm{AB}}$ & $44.9 \pm 0.9^{\mathrm{AB}}$ & $177 \pm 30^{\text {bcde }}$ & $218 \pm 35^{b}$ \\
\hline & GC & $61.7 \pm 2.5^{c}$ & $71.9 \pm 4.1^{\mathrm{abc}}$ & $22.2 \pm 1.6^{\mathrm{GH}}$ & $39.8 \pm 1.5^{\mathrm{BC}}$ & $75 \pm 12^{9}$ & $139 \pm 30^{\text {de }}$ \\
\hline & LD & $65.3 \pm 6.1^{\mathrm{abc}}$ & $74.3 \pm 2.4^{\mathrm{ab}}$ & $27.0 \pm 5.8^{F G}$ & $43.8 \pm 0.4^{\mathrm{AB}}$ & $129 \pm 29 e$ & $187 \pm 26^{\text {bcd }}$ \\
\hline & $\mathrm{MH}$ & $65.2 \pm 4.7^{\mathrm{abc}}$ & $74.3 \pm 1.1^{\mathrm{ab}}$ & $37.0 \pm 2.6^{\mathrm{CD}}$ & $43.9 \pm 1.8^{\mathrm{AB}}$ & $177 \pm 11^{\text {bcde }}$ & $211 \pm 17^{b}$ \\
\hline & MF & $61.5 \pm 4.4^{c}$ & $74.2 \pm 3.5^{\mathrm{ab}}$ & $31.5 \pm 2.1 \mathrm{EF}$ & $45.9 \pm 2.1^{\mathrm{A}}$ & $132 \pm 22^{e}$ & $204 \pm 14^{b c}$ \\
\hline
\end{tabular}


The second hypothesis of this study, which stated that the resin cement properties are influenced by differences in irradiance and spectral emission between the LED and QTH unit, was partially confirmed. Though LED spectral emission was more concentrated between 425 and $490 \mathrm{~nm}$ and presented higher irradiance than QTH, no statistically significant differences in DC and Knoop microhardness were verified between LED and QTH, except for the hardness of the dual-cured cement specimens photoactivated through LD (LED>QTH). A previous study reported that the use of high irradiances resulted in consistently higher mechanical properties of resin-based materials. ${ }^{32}$ Howev$\mathrm{er}$, when the irradiance exceeds $600 \mathrm{~mW} / \mathrm{cm}^{2}$, as occurred in the present study, the differences between units was not significant. 24,32 Regarding the flexural strength, the use of QTH resulted in 15\% higher strength than the LED. However, considering the non-significant third-order interaction, strength was higher with QTH than with LED only with MF in light-cure mode and with the control and the $\mathrm{MH}$ groups in dual-cure mode.

The lower irradiance of QTH probably was offset by the higher wavelength range. We observed that the light transmittance through restorative materials increased with the increase of wavelength. This is in accordance with the Rayleigh scattering equation, which states that the higher the wavelengths, the lower the light scattering. ${ }^{33,44}$ Thus, the higher the wavelength emitted by the curing light, the higher the transmittance. The fact that the influence of the curing unit was observed only in flexural strength may be explained by the fact that this property is more influenced by the DC reached at the non-irradiated surface of the specimen. As specimen failure initiates at the bottom surface of the specimen and all specimens were positioned with the irradiated surface toward the load application, a lower DC at the non-irradiated surface of the specimen would lead to a reduced flexural strength. This reduced level of DC was not shown in KHN results because they are the average of six indentations performed on the lateral surface of the specimen. In fact, a previous study that compared QTH and LED found that at deep regions of the composite specimen, due to the high light scattering promoted by the filling as a consequence of low wavelengths, LED irradiance drops more severely than irradiance of QTH. ${ }^{31}$
It is known that a reduction in light irradiance can be counterbalanced by increasing the exposure time of the composite to the light source. ${ }^{45} \mathrm{It}$ was reported that the resin cement, in both activation modes, cured through porcelain or cast glass ceramic specimens with a thickness of $1.0 \mathrm{~mm}$ or less was thoroughly polymerized with a 60 -second exposure time. ${ }^{46}$ Another study showed that a 60 $\mathrm{s}$ exposure time did not provide adequate polymerization of the resin cements in light-cure mode through porcelain discs with $0.75 \mathrm{~mm}$ thickness; however, when the catalyst was used, exposure times longer than $60 \mathrm{~s}$ did not provide any significant changes in hardness..$^{39}$ Based on that finding, the exposure time used in the present study was $60 \mathrm{~s}$, above the $40 \mathrm{~s}$ recommended by the cement manufacturer.

Further investigation is necessary with different restorative materials, resin cements, and curing units, using other mechanical tests or even adhesion tests to confirm the results. Due to the resin cement thickness and the absence of aging mechanisms, the results of the present study cannot predict or summarize the performance and longevity of an aesthetic indirect restoration.

\section{CONCLUSIONS}

- Among the restorative materials evaluated, the micro-hybrid composite presented the highest transmittance.

- The resin cement in light-cure mode showed lower DC than in dual-cure mode. However, it was not possible to affirm that the attenuation caused by the restorative materials was responsible for this occurrence.

- When the resin cement was tested in lightcure mode, the light attenuation caused by the restorative materials negatively affected its microhardness.

- The light attenuation caused just by GC and LD with QTH and GC with LED decreased the flexural strength of the cement in both activation modes.

- Though LED spectral emission was closer to the camphorquinone absorbance range and presented higher irradiance than QTH, no statistically significant differences in DC and Knoop microhardness were verified, except for LD/LED in dual-cure mode. 


\section{ACKNOWLEDGEMENTS}

This study was partially supported by the federal grant agency CNPq (Conselho Nacional de Desenvolvimento Científico e Tecnológico), Brazil. The authors would like to thank the reviewers for the pertinent and useful suggestions they made about the manuscript.

\section{REFERENCES}

1. Attar N, Tam LE, McComb D. Mechanical and physical properties of contemporary dental luting agents. J Prosthet Dent 2003;89:127-134.

2. Li ZC, White SN. Mechanical properties of dental luting cements. J Prosthet Dent 1999;81:597-609.

3. Michelini FS, Belser UC, Scherrer SS, De Rijk WG. Tensile bond strength of gold and porcelain inlays to extracted teeth using three cements. Int J Prosthodont 1995;8:324331.

4. Rosenstiel SF, Land MF, Crispin BJ. Dental luting agents: A review of the current literature. J Prosthet Dent 1998;80:280301.

5. Kucukesmen HC, Usumez A, Ozturk N, Eroglu E. Change of shade by light polymerization in a resin cement polymerized beneath a ceramic restoration. J Dent 2008;36:219223.

6. Cardash HS, Baharav H, Pilo R, Ben-Amar A. The effect of porcelain color on the hardness of luting composite resin cement. J Prosthet Dent 1993;69:620-623.

7. Rasetto FH, Driscoll CF, Prestipino V, Masri R, von Fraunhofer JA. Light transmission through all-ceramic dental materials: A pilot study. J Prosthet Dent 2004;91:441-446.

8. Soares CJ, da Silva NR, Fonseca RB. Influence of the feldspathic ceramic thickness and shade on the microhardness of dual resin cement. Oper Dent 2006;31:384-389.

9. Braga RR, Cesar PF, Gonzaga CC. Mechanical properties of resin cements with different activation modes. J Oral Rehabil 2002;29:257-262.

10. el-Badrawy WA, el-Mowafy OM. Chemical versus dual curing of resin inlay cements. J Prosthet Dent 1995;73:515-524.

11. Hofmann N, Papsthart G, Hugo B, Klaiber B. Comparison of photo-activation versus chemical or dual-curing of resinbased luting cements regarding flexural strength, modulus and surface hardness. J Oral Rehabil 2001;28:10221028.

12. Jung $H$, Friedl KH, Hiller KA, Furch $H$, Bernhart $S$, Schmalz $G$. Polymerization efficiency of different photocuring units through ceramic discs. Oper Dent 2006;31:68-77.

13. Ozyesil AG, Usumez A, Gunduz B. The efficiency of different light sources to polymerize composite beneath a simulated ceramic restoration. J Prosthet Dent 2004;91:151-157.
14. Callister WD. Materials Science and Engineering: An Introduction. $5^{\text {th }}$ Ed. New York. John Wiley \& Sons. 1999.

15. Heffernan MJ, Aquilino SA, Diaz-Arnold AM, Haselton DR, Stanford CM, Vargas MA. Relative translucency of six allceramic systems. Part I: core materials. J Prosthet Dent 2002;88:4-9

16. Heffernan MJ, Aquilino SA, Diaz-Arnold AM, Haselton DR, Stanford CM, Vargas MA. Relative translucency of six allceramic systems. Part II: core and veneer materials. $J$ Prosthet Dent 2002;88:10-15.

17. Cook WD. Photopolymerization kinetics of dimethacrylates using the camphorquinone/amine initiator system. Polymer 1992;33600-33609.

18. Neumann MG, Schmitt CC, Ferreira GC, Correa IC. The initiating radical yields and the efficiency of polymerization for various dental photoinitiators excited by different light curing units. Dent Mater 2006;22:576-584.

19. Lu H, Mehmood A, Chow A, Powers JM. Influence of polymerization mode on flexural properties of esthetic resin luting agents. J Prosthet Dent 2005;94:549-554.

20. O'Keefe KL, Pease PL, Herrin HK. Variables affecting the spectral transmittance of light through porcelain veneer samples. J Prosthet Dent 1991;66:434-438.

21. Akgungor G, Akkayan B, Gaucher $H$. Influence of ceramic thickness and polymerization mode of a resin luting agent on early bond strength and durability with a lithium disilicate-based ceramic system. J Prosthet Dent 2005;94:234241.

22. Kawaguchi M, Fukushima T, Miyazaki K. The relationship between cure depth and transmission coefficient of visiblelight-activated resin composites. J Dent Res 1994;73:516521.

23. Uctasli S, Hasanreisoglu U, Wilson HJ. The attenuation of radiation by porcelain and its effect on polymerization of resin cements. J Oral Rehabil 1994;21:565-575.

24. Barghi N, McAlister EH. LED and halogen lights: Effect of ceramic thickness and shade on curing luting resin. Comp Cont Educ Dent 2003;24:497-500.

25. El-Mowafy OM, Rubo MH. Influence of composite inlay/onlay thickness on hardening of dual-cured resin cements. $J$ Can Dent Assoc 2000;66:147.

26. El-Mowafy OM, Rubo MH, El-Badrawy WA. Hardening of new resin cements cured through a ceramic inlay. Oper Dent 1999;24:38-44.

27. Nalcaci A, Kucukesmen C, Uludag B. Effect of high-powered LED polymerization on the shear bond strength of $a$ light-polymerized resin luting agent to ceramic and dentin. J Prosthet Dent 2005;94:140-145. 
28. Jung $H$, Friedl KH, Hiller KA, Haller A, Schmalz G. Curing efficiency of different polymerization methods through ceramic restorations. Clin Oral Investig 2001;5:156-161.

29. Park SH, Kim SS, Cho YS, Lee CK, Noh BD. Curing units' ability to cure restorative composites and dual-cured composite cements under composite overlay. Oper Dent 2004;29:627-635.

30. Price RB, Felix CA, Andreou P. Evaluation of a dual peak third generation LED curing light. Comp Cont Educ Dent 2005;26:331-332.

31. Santos GB, Medeiros IS, Fellows CE, Muench A, Braga RR. Composite depth of cure obtained with QTH and LED units assessed by microhardness and micro-Raman spectroscopy. Oper Dent 2007;31:79-83.

32. Santos GC, Jr., El-Mowafy O, Rubo JH, Santos MJ. Hardening of dual-cure resin cements and a resin composite restorative cured with QTH and LED curing units. $J$ Can Dent Assoc 2004;70:323-328.

33. Brodbelt RH, O'Brien WJ, Fan PL. Translucency of dental porcelains. J Dent Res 1980;59:70-75.

34. Kumbuloglu O, Lassila LV, User A, Vallittu PK. A study of the physical and chemical properties of four resin composite luting cements. Int J Prosthodont 2004;17:357-363.

35. Poskus LT, Placido E, Cardoso PE. Influence of placement techniques on Vickers and Knoop hardness of class II composite resin restorations. Dent Mater 2004;20:726-732.

36. Muench A, Correa IC, Grande RHM, João M. The effect of specimen dimensions on the flexural strength of a composite resin. J Appl Oral Sci 2005;13:265-268.

37. Papazoglou E, Rahiotis C, Kakaboura A, Loukidis M. Curing efficiency of a photo- and dual-cured resin cement polymerized through 2 ceramics and a resin composite. Int $J$ Prosthodont 2006;19:34-36.

38. Caughman WF, Chan DC, Rueggeberg FA. Curing potential of dual-polymerizable resin cements in simulated clinical situations. J Prosthet Dent 2001;85:479-484.

39. Linden JJ, Swift EJ, Jr., Boyer DB, Davis BK. Photo-activation of resin cements through porcelain veneers. J Dent Res 1991;70:154-157.

40. Tango RN, Sinhoreti MA, Correr AB, Correr-Sobrinho $L$, Consani RL. Effect of veneering materials and curing methods on resin cement Knoop hardness. Br Dent $\mathrm{J}$ 2007;18:235-239

41. Zhang Y, Griggs JA, Benham AW. Influence of powder/ liquid mixing ratio on porosity and translucency of dental porcelains. J Prosthet Dent 2004;91:128-135.

42. Pilo R, Cardash HS. Post-irradiation polymerization of different anterior and posterior visible light-activated resin composites. Dent Mater 1992;8:299-304.
43. Watts DC, Cash AJ. Analysis of optical transmission by 400-500 nm visible light into aesthetic dental biomaterials. J Dent 1994;22:112-117.

44. Dias MC, Piva E, de Moraes RR, Ambrosano GM, Sinhoreti MA, Correr-Sobrinho L. UV-Vis spectrophotometric analysis and light irradiance through hot-pressed and hot-pressed-veneered glass ceramics. Braz Dent $J$ 2008;19:197-203.

45. Watts DC, Amer O, Combe EC. Characteristics of visiblelight-activated composite systems. Br Dent J 1984;156:209215.

46. Blackman R, Barghi N, Duke E. Influence of ceramic thickness on the polymerization of light-cured resin cement. $J$ Prosthet Dent 1990;63:295-300. 